www.jmscr.igmpublication.org

Index Copernicus Value: 79.54

ISSN (e)-2347-176x ISSN (p) 2455-0450

crossrefDOI: https://dx.doi.org/10.18535/jmscr/v7i1.111

\title{
An Observational Study to Look for the Incidence of Postoperative Burst Abdomen in Patients of Anemia
}

\author{
Authors \\ Vinit Kumar Tiwari ${ }^{1}$, Ashutosh Silodia ${ }^{2}$, Munna Kalme ${ }^{3}$
}

\begin{abstract}
Background: Burst abdomen is a major post-operative complication encounterd by Surgeons routinely. Anemia is one of the known predisposing factors leading to burst abdomen which should be taken in consideration in order to prevent burst abdomen to some extent.

Aim: To evaluate the incidence of burst abdomen in patients of anemia undergoing emergency laprotomy for any surgical indications.

Method: The present study was conducted among 210 patients who underwent emergency laparotomy by midline incisions. All patients between 18 to 75 years were taken into account that underwent laprotomy. Predisposing factors especially anemia were recorded preoperatively contributing to burst abdomen.

Results: Out of 210 patients operated, 51 developed burst abdomen with a percentage of 24.28\%.The frequency of burst abdomen was significantly higher in older age group as compared to younger. Anemia was found as a major risk factor in $31.7 \%$ of the patients developing burst abdomen who were anaemic preoperatively with majority of patients falling in moderate and severe anaemic groups.

Conclusion: Burst abdomen is a surgical emergency with high morbidity and mortality leading to a prolonged illness. Anemia is a major determinant predisposing to burst abdomen and sufficient amount of data has to be collected in order to address the disease burden.

Keywords: Burst abdomen, laprotomy, postoperative, anemia.
\end{abstract}

\section{Introduction}

Every surgery is associated with some postoperative complication weather it is a elective surgery or emergency surgery, commen postoperative complications are wound infection, burst abdomen, incisional hernia, anastomotic leak, intestinal adhesion, intestinal obstruction, intestinal fistula, stoma dehiscenes, stoma herniation and many more.

Burst abdomen is serious post operative complication with high mortality rate as high as $45 \%^{1}$.world wide reported incidence ranges from
0.4 to $3.5 \% \%^{2-4}$,where as in our country frequency of burst abdomen ranges from 5.3 to $8.3 \%$.,6

Following emergency surgery superficial and deep tissue separation cause wound dehiscence, Which ultimately leads to severity in form of wound gaping and burst abdomen. There are many other factors which predispose to burst abdomen has been studied including anemia ${ }^{7-9}$.in our present study author wants to find the incidence of anemia as a predisposing factor in the development of burst abdomen so that factors like anemia can be addresed to prevent such a devastating condition like burst abdomen. 


\section{JMSCR Vol||07||Issue||01||Page 655-658||January}

\section{Material and Methods}

The present study was conducted among 210 patients who underwent emergency laparotomy by midline incisions in Department of Surgery N.S.C.B. Medical College \& Hospital Jabalpur (M.P.) India. Duration of Study was from $1^{\text {st }}$ March 2016 to $31^{\text {st }}$ August 2017.allPatients who have undergone emergency laprotomy for any indication from age $>18 \mathrm{yrs}$ and $<75 \mathrm{yrs}$ and of either sex who have developed abdominal burst Abdomen were included.

This is a Prospective and observational study involving all those who have developed burst abdomen after laprotomy. An elaborative study of these cases with regard to clinical history, significant risk factors, investigations, time of surgery and type of surgery and postoperatively, study of diagnosis and day of diagnosis of burst abdomen is done till the patient is discharged from the hospital. In history, details regarding presenting complaints, duration, associated diseases, significant risk factors including, anaemia were noted. Postoperatively burst Abdomen was diagnosed.

\section{Results}

The mean age of the cases $(45.29 \pm 18.03)$ with burst abdomen was found significantly higher than those where burst abdomen was absent (39. 62 \pm 15.53$)$. ( $\mathrm{P}>0.05)$.

- In cases where burst Abdomen was present $86.3 \%$ were males and $13.7 \%$ were females significantly in another category where burst abdomen was not present male cases were $81.8 \%$ and female no significant association between gender and burst abdomen and were seen $\left(\mathrm{x}^{2}=0.554 ; \mathrm{P}>0.005\right)$ TABLE- 2 .

- Out of 145 pateints who were anaemic preoperatively 46 pateints developed burst abdomen( $31.7 \%$ ). whereas out of 65 patients who were non anaemic only 5 pateints developed burst abdomen(7.70\%). Statistically higher proportion of anaemia was present in the cases of burst abdomen. Overall out of 210 pateints 51 (24.30\%) developed burst abdomen (TABLE-3) and GRAPH-1.

Table- 4 and Graph-2 defines about the Hb level finding in studied cases. In Burst abdomen Group in $42.9 \%$ observed with $<7$ severe $\mathrm{Hb}$ levels $38.7 \%$ in $7-10$ moderate Hb levels, $10.3 \%$ in mild $10-12 \mathrm{gm} / \mathrm{dl}$ and $11.9 \%$ were seen with normal $\mathrm{Hb}$ levels. While in other category this proportional were $57.1 \%$ in severe $<735.61 .3 \%$ in $7-10$ moderate, $89.7 \%$ in $10-12$ mild and $88.1 \%$ in $>12$ normal $\mathrm{Hb}$ level. Statistically the burst abdomen group cases found with significantly lower to moderate $\mathrm{Hb}$ levels $(\mathrm{P}<0.05)$.

Table No 1 Age Distributions

\begin{tabular}{|l|c|c|c|}
\hline \multirow{2}{*}{$\begin{array}{l}\text { Age } \\
\text { Group }\end{array}$} & \multicolumn{2}{|c|}{ Burst Abdomen } & \multirow{2}{*}{ Total } \\
\cline { 2 - 4 } $20-29$ & No & Yes & \\
\cline { 2 - 4 } & $81.00 \%$ & 11 & 58 \\
\hline \multirow{2}{*}{$30-39$} & 34 & 9 & $100.00 \%$ \\
\cline { 2 - 4 } & $79.10 \%$ & $20.90 \%$ & $100.00 \%$ \\
\hline \multirow{3}{*}{$40-49$} & 33 & 8 & 41 \\
\cline { 2 - 4 } & $80.50 \%$ & $19.50 \%$ & $100.00 \%$ \\
\hline \multirow{3}{*}{$50-59$} & 19 & 10 & 29 \\
\cline { 2 - 4 } & $65.50 \%$ & $34.50 \%$ & $100.00 \%$ \\
\hline \multirow{2}{*}{$60-69$} & 21 & 7 & 28 \\
\cline { 2 - 4 } & $75.00 \%$ & $25.00 \%$ & $100.00 \%$ \\
\hline \multirow{2}{*}{$>70$} & 5 & 6 & 11 \\
\cline { 2 - 4 } & $45.50 \%$ & $54.50 \%$ & $100.00 \%$ \\
\hline \multirow{2}{*}{ Total } & 159 & 51 & 210 \\
\cline { 2 - 4 } & $75.70 \%$ & $24.30 \%$ & $100.00 \%$ \\
\hline
\end{tabular}

$\mathrm{t}=2.02 ; \mathrm{P}<0.03$

Table No. -2 Gender Distributions

\begin{tabular}{|c|c|c|c|}
\hline \multirow{2}{*}{ Sex } & \multicolumn{2}{|c|}{ Burst Abdomen } & \multirow{2}{*}{ Total } \\
\hline & No & Yes & \\
\hline \multirow{2}{*}{ Male } & 130 & 44 & 174 \\
\hline & $74.70 \%$ & $25.30 \%$ & $100.00 \%$ \\
\hline \multirow{2}{*}{ Female } & 29 & 7 & 36 \\
\hline & $80.60 \%$ & $19.40 \%$ & $100.00 \%$ \\
\hline \multirow{2}{*}{ Total } & 159 & 51 & 210 \\
\hline & $75.70 \%$ & $24.30 \%$ & $100.00 \%$ \\
\hline
\end{tabular}

Table No. 3 Anemia Burst Abdomen Cross tabulation

\begin{tabular}{|l|c|c|c|}
\hline \multirow{2}{*}{ Anemia } & \multicolumn{2}{|c|}{ Burst Abdomen } & \multirow{2}{*}{ Total } \\
\cline { 2 - 4 } & No & Yes & \\
\hline \multirow{2}{*}{ Yes } & 99 & 46 & 145 \\
\cline { 2 - 4 } & $68.30 \%$ & $31.70 \%$ & $100.00 \%$ \\
\hline \multirow{2}{*}{ No } & 60 & 5 & 65 \\
\cline { 2 - 4 } & $92.30 \%$ & $7.70 \%$ & $100.00 \%$ \\
\hline \multirow{2}{*}{ Total } & 159 & 51 & 210 \\
\cline { 2 - 4 } & $75.70 \%$ & $24.30 \%$ & $100.00 \%$ \\
\hline$\chi^{2}=14.096 ; \mathrm{P}<0.0001$ & &
\end{tabular}


Table No. 4 HB Level Burst Abdomen Cross tabulation

\begin{tabular}{|c|c|c|c|}
\hline \multirow{2}{*}{ Hb Level } & \multicolumn{2}{|c|}{ Burst Abdomen } & \multirow{2}{*}{ Total } \\
\hline & No & Yes & \\
\hline \multirow{2}{*}{$<7$ Severe } & 4 & 3 & 7 \\
\hline & $57.10 \%$ & $42.90 \%$ & $100.00 \%$ \\
\hline \multirow{2}{*}{$\begin{array}{l}-10 \\
\text { Moderate }\end{array}$} & 57 & 36 & 93 \\
\hline & $61.30 \%$ & $38.70 \%$ & $100.00 \%$ \\
\hline \multirow{2}{*}{ 10-12 Mild } & 61 & 7 & 68 \\
\hline & $89.70 \%$ & $10.30 \%$ & $100.00 \%$ \\
\hline \multirow{2}{*}{$\begin{array}{ll}> & 12 \\
\text { Normal } & \end{array}$} & 37 & 5 & 42 \\
\hline & $88.10 \%$ & $11.90 \%$ & $100.00 \%$ \\
\hline \multirow{2}{*}{ Total } & 159 & 51 & 210 \\
\hline & $75.70 \%$ & $24.30 \%$ & $100.00 \%$ \\
\hline
\end{tabular}

Graph No. 1 Anemia Burst Abdomen Cross tabulation

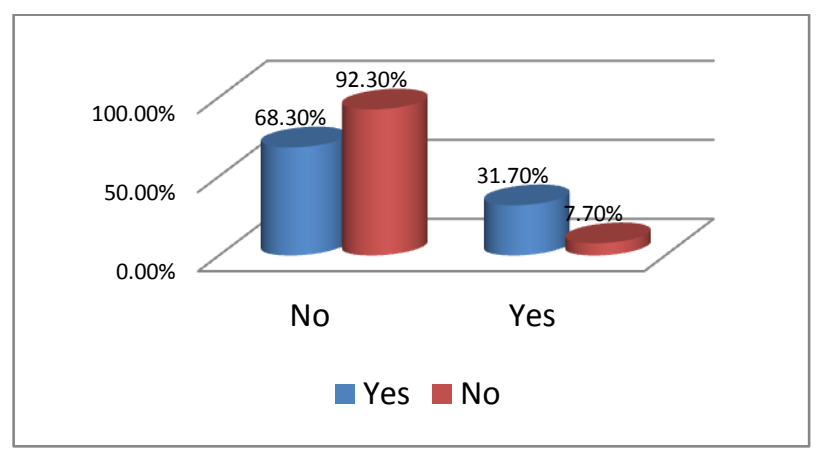

Graph No. - 2 HB Level Burst Abdomen Cross tabulation

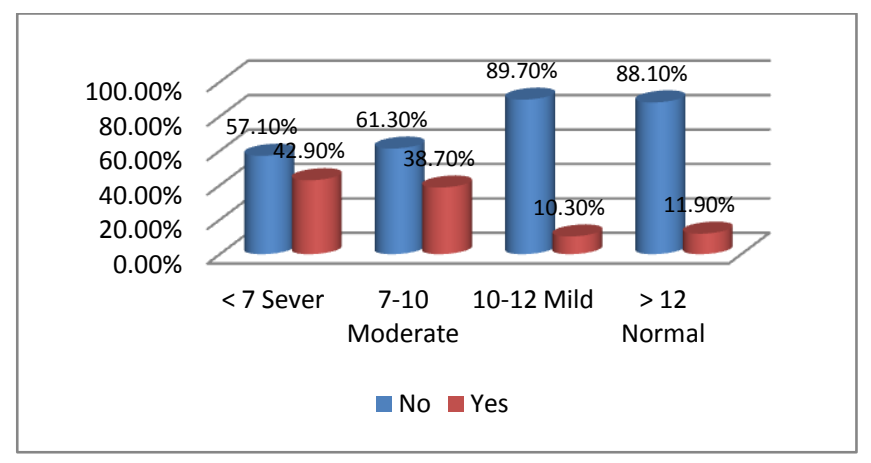

\section{Discussion}

Burst abdomen after laparotomy is a surgical emergency with high morbidity and mortality leading to longer in hospital stay and prolonged illness. This complication can be avoided if the factors involved in wound dehiscence are properly understood, Anemia and hypoproteinemia are known risk factors in wound healing ${ }^{10}$. In the present study author laid emphasis on the incidence of burst abdomen in anaemic patients.

Sony et $\mathrm{al}^{11}$ did a study 2015, A total of 162 patients who underwent laprotomy. The mean age of patients was $47.32 \pm 12.644$ years. The number of male patients was 94 and female patients were 68. He evaluated the common risk factors associated with burst abdomen and found the incidence of anemia (12.4\%) next only to malnutrition and obesity.

Sinha et $\mathrm{al}^{12}$ did a study in 2015 , In this study out of 57 patients of burst abdomen about $43.8 \%$ of patients showed hemoglobin $<10 \mathrm{gm} \%$ along with other risk factors including, Age, Poor Nutritional status, Obesity, Diabetes Mellitus, Hypoproteinemiaetc

Keil et $\mathrm{al}^{13}$ performed a study in 1973 , In this study Patients were considered anemic if their preoperative hematocrit values were below laboratory normals (42\% for males and $37 \%$ for females). There were $27(57.4 \%$ ) anaemic patients in the group with dehiscence and 19(32.8\%) in the sample without it. This difference is significant by the $\chi^{2}$ statistic $(\mathrm{P}<.02)$.

Garg et $\mathrm{al}^{14}$ performed a study in 2014 , This was a prospective study done on 50 patients who developed wound dehiscence following laparotomy. In this study, 13 patients (26\%) were anemic with $\mathrm{Hb}$ of less than $10 \mathrm{~g} \%$.

Where as in the present study author finds, Out of 145 patients who were anaemic preoperatively 46 patients developed burst abdomen (31.7\%) which is comparable to other studies. whereas out of 65 pateints who were non anaemic only 5 pateints developed burst abdomen(7.70\%). statistically higher proportion of anaemia was present in the cases of burst abdomen $\left(\chi^{2} 14.096 ; \mathrm{P}<0.0001\right)$.

\section{Conclusion}

Burst abdomen is a severe sequale of impaired wound healing many factors can predispose to this serious problem such as anemia, hypoprotinemia, obsesity. Coughing, distension, malnutrition post operatively. but since this morbid condition is commonly encountered in routine practice special attention is to be given to each variable separately like anemia and many research work has to be done in order to prevent and treat wisely. 


\section{References}

1. Fleischer GM, Rennert A,Rühmer $\mathbf{M}$. Infected abdominal wall and burst abdomen. Chirurg 2000;71:754-62

2. Swaroop M, Williams M, Greene WR, Sava J, Park K, Wang D. Multiple laparotomies are a predictor of fascial dehiscence in the setting of severe trauma. Am Surg 2005;71:402-5.

3. Waqar SH, Malik ZI, Razzaq A, Abdullah MT, Shaima A, Zahid MA. Frequency and risk factors for wound dehiscence/burst abdomen in midline laparotomies. J Ayub Med Coll Abbottabad 2005;17:70-3.

4. Kirshtein B, Roy-Shapira A, Lantsberg L, Mizrahi S. Use of the "Bogota bag" for temporary abdominal closure in patients with secondary peritonitis. Am Surg 2007;73:249-522.

5. Adnan A, Shams NA, Irfan S, Manzar S. Abdominal wound dehiscence: An ongoing dilemma. Pak J Surg 2009;25: 204-8.

6. Shaikh MS, Shaikh SA, Shaikh BA. Abdominal wound dehiscence: Frequency and risk factors. J Surg Pak 2005; 10:30-3.

7. Parmar G, Gohil A, Hathila V. Burst abdomen: A grave postoperative complication. Internet J Surg 2008;20:1-8.

8. Gürleyik G. Factors affecting disruption of surgical abdominal incisions in early postoperative period. Ulus Travma Derg 2001;7:96-9

9. Goligher JC, Irvin TT, Johnston D, De Dombal FT, Hill GL, Horrocks JC. A controlled clinical trial of three methods of closure of laparotomy wounds. Br J Surg 1975;62:823-9.

10. D. A. Dubay and M. G. Franz, "Acute Wound Healing: The Biology of Acute Wound Failure," Surgical Clinics of North America, Vol. 83, No. 3, 2003, pp. 463481.

11. Soni P, Haripriya VB, Haripriya A, Dutt V. Burst Abdomen: A Post-operative
Morbidity in Medical College, Bilaspur, India. Int J Sci Stud 2015;3(6):175-178

12. Sinha A, Jayanth DH, Saurabh P, Srihari SR, Uthraa RT. Wound dehiscence still a post-operative morbidity: A retrospective study. J Evid Based Med Healthc 2015;2:5712-7.

13. Keill RH, Keitzer WF, Nichols WK. Abdominal wound dehiscence. Arch Surg. 1973; 106: 573-7.

14. Gar G ramnee Sh, Shah Sheerin, SinGh Surinder, Sin Gh Bir. A Prospective Study of Predictors for Post-laparotomy Abdominal Wound Dehiscence: Journal of Clinical and Diagnostic Research. 2014 Jan, Vol-8(1): 80-83. 